\section{P1-312 SOCIOECONOMIC INEQUALITY AND UNINTENTIONAL INJURIES AMONG CHILDREN IN TEHRAN, FINDINGS OF URBAN HEART PROJECT}

doi:10.1136/jech.2011.142976f.4

\begin{abstract}
${ }^{1,2} \mathrm{R}$ Safari-Faramani, ${ }^{*}{ }^{1,2} \mathrm{~S}$ A Motevalian, ${ }^{1,2} \mathrm{M}$ Asadi-Lari, ${ }^{3} \mathrm{M}$ R Vaez-Mahdavi, ${ }^{4} S$ Faghihzadeh, ${ }^{5} \mathrm{~A}$ Montazeri, ${ }^{1} \mathrm{H}$ Malek-Afzali. ${ }^{1}$ Tehran University of Medical Sciences, Tehran, Iran; ${ }^{2}$ School of Public Health, Tehran, Iran; ${ }^{3}$ Shahed University, Tehran, Iran; ${ }^{4}$ Tarbiat Modarres University, Tehran, Iran; ${ }^{5}$ Iranian Institute for Health Sciences Research, Thran, Iran
\end{abstract}

Introduction The assessment phase of Urban Health Equity Assessment and Response Tool (urban HEART) project was carried out in Tehran in 2008. The objective of this study is to determine the socioeconomic inequality in unintentional injuries in children $<5$ years of age using the survey data

Method More than 21000 households contain 81418 individuals were randomly selected by a three-stage sampling scheme. The sample included 4394 subjects $<5$ years old. In each household, the respondents were asked to describe all unintentional injuries occurred for any of the household members during past 12 months which needed treatment in a medical facility or caused to at least 1 day loss of normal life activities. Asset data was used for assessment of the socioeconomic status by applying principal component analysis. To measure inequalities, concentration indices were calculated for each type of unintentional injuries.

Results Annual incidence rate for all injuries was 33.0 (95\% CI 28.1 to 38.7 ) per 1000 person years. It was 47.8 (95\% CI 35.5 to 64.0$)$ per 1000 person years for the poorest and 19.3 (95\% CI 12.1 to 30.8 ) for the richest quintile. Concentration index for all types of unintentional injuries was $-0.40(\mathrm{SE}=0.07)$. Concentration indices for traffic injuries, falls, burns and poisonings were -0.41 ( $\mathrm{SE}=0.09)$, $-0.37(\mathrm{SE}=0.07),-0.62(\mathrm{SE}=0.21)$ and $-0.35(\mathrm{SE}=0.9)$ respectively.

Conclusion Results of this study showed substantial differences in children's unintentional injuries between socioeconomic groups. Although the first phase of Urban HEART project was primarily intended to measure inequality in health among urban communities; it is expected that appropriate responses undertake to modify the observed inequalities.

\section{P1-313 WORK-RELATED FACTORS OF INSOMNIA AMONG HOSPITAL DOCTORS}

doi:10.1136/jech.2011.142976f.5

${ }^{1} Y$ Saijo, ${ }^{*}{ }^{1} Y$ Nakagi, ${ }^{1} \mathrm{~T}$ Ito, ${ }^{1} Y$ Sugioka, ${ }^{1} \mathrm{H}$ Okazaki, ${ }^{1} \mathrm{~T}$ Yoshida, ${ }^{2} \mathrm{Y}$ Tamura, ${ }^{2} \mathrm{~S}$ Chiba. ${ }^{1}$ Department of Health Science, Asahikawa Medical University, Asahikawa, Japan; ${ }^{2}$ Department of Psychiatry and Neurology, Asahikawa Medical University, Asahikawa, Japan

Introduction This study aimed to elucidate the relationship of night duty, on-call duty, average working hours and job stress to insomnia among hospital doctors.

Methods Questionnaires including job factors and the Brief Job Stress Questionnaire, were sent to all alumni of Asahikawa Medical University ( $\mathrm{n}=2937)$. Of the 568 medical doctors who responded, 430 were hospital doctors; 424 questionnaires were analysed after excluding six because of missing values. Insomnia was estimated using the Athens Insomnia Scale ( $\geq 6$ points). Explanatory variables were sex, age, specialty, location, night duty, on-call duty, average working hours, job effort, level of job control, support from supervisors, support from co-workers and support from family/friends. Logistic regression analysis was used; sex, age and specialty were forced into the model and other variables were entered into the model in a reverse stepwise manner.
Results In the stepwise logistic regression analysis, night duty had a significantly higher $\mathrm{OR}$ for insomnia $(\mathrm{OR}=2.00$; 95\% CI 1.24 to 3.27). A high levels of job control and high job support had a significantly lower ORs (OR $=0.76,95 \%$ CI 0.68 to 0.86 ; $O R=0.88$, $95 \%$ CI 0.79 to 0.98 , respectively). Average working hours was selected in final model but the relationship was not significant. The other variables were not selected in the final model.

Conclusion Night duty may induce insomnia, but a high level of job control and a high level of support from co-workers may have a protective effect against insomnia among hospital doctors.

\section{P1-314 KNOWLEDGE, PERCEPTIONS AND PRACTICES CONCERNING PAP SMEAR SCREENING FOR CERVICAL CANCER IN LEBANON}

doi:10.1136/jech.2011.142976f.6

R Sakr, ${ }^{*}$ S Adib. Faculty of Medicine, Saint-Joseph University, Beirut, Lebanon

Objective Determine the effect of sociodemographic and gynaecological characteristics of Lebanese women aged 18 to 65, and the effect of their knowledge and perceptions on the prevalence of use of Pap smear.

Methods This cross-sectional study randomly sampled 2255 women. The questionnaire was based upon "Health Belief Model". The use of Pap smear was distributed: "never", "old", "recent".

Results The weighted prevalence was 35\% (24\% "old", $11 \%$ of "recent"). This was significantly correlated with older age, capital residence, marital status, high education of women and husbands, with the fact that most women don't work, with higher professional level of the husband, with maximum health coverage and lesser crowding index. This prevalence was not significantly correlated with sexual practices. Knowledge did not affect significantly the practice, except knowing the utility of screening and being in contact with women who did the test or who have cancer. The use of Pap smear was significantly related to the scores of perception of susceptibility, barriers, advantages and motivators. Only the perception of severity did not significantly affect the use.

Conclusion The prevalence of use is far from international rates. The absence of national screening programs and of medical referrals explains. Although women know the utility of Pap smear, it is not knowledge of the aetiology of cervical cancer that got them one. The prevalence was blocked by:embarrassment, cost and accessibility. The perception of barriers minimised all others. This study proposes to: organise targeted campaigns, develop a national program of screening and decide of HPV vaccination.

\section{P1-315 EPIDEMIOLOGICAL PROFILE OF LEPROSY IN AN ESF PAULO AFONSO/BA IN 2009}

doi:10.1136/jech.2011.142976f.7

K C S Alves, * B F S Oliveira. Prefeitura Municipal de Paulo Afonso, Paulo Afonso, Bahia, Brazil

Leprosy is considered a public health problem that can be monitored using the methods currently available. In Brazil, a country with higher prevalence in the world, this control is one of the actions attributed to the Family Health Strategy. The purpose of this study was to build a network of knowledge about the epidemiological profile of leprosy patients in 2009 to a Family Health Team's Paulo Afonso/BA. The objective was to identify the particular mode of manifestation of the patients studied. The sample consisted of 27 leprosy patients who attended for treatment along with the ESF in 
2009, a period that was conducted to collect data. Through a quantitative approach, number of fundamental importance to this study, because through their meanings becomes profitable and easy to control. The results show that 13 patients had 40 to 60 years of age and 14 were between 10 and 39 years, 70\% were female and the majority consisted of low-income people and poor literacy. Of the patients, $70 \%$ were paucibacillary and multibacillary remaining $30 \%$. The results indicate that patients with leprosy showed the need for educational interventions to prevent and knowledge of the disease and also actions aimed at planning assistance to leprosy patients were included in these lawsuits nursing care.

\section{P1-316 POPULATION IMPACT AND APPROPRIATENESS OF TREATMENT ACCORDING TO DIFFERENT OSTEOPOROSIS GUIDELINES}

doi:10.1136/jech.2011.142976f.8

G Sanfélix-Gimeno, ${ }^{*}$ I Hurtado, S Peiró, J Sanfélix-Genovés. Centre for public health research, Valencia, Spain

Introduction The aim of this study was to evaluate the impact and appropriateness of treatment according to different osteoporosis guidelines (National Osteoporosis Foundation (NOF), Community of Madrid (CMA) and General Practitioners' Society (SEMERGEN)) in women over 50 years in Spain

Method Cross-sectional study conducted between 2006 and 2007 in Valencia, Spain. An age-stratified population-based random sample of 824 postmenopausal women over 50 answered a questionnaire about risk factors and anti-osteoporotic treatment, and received a lumbar spine and hip densitometry and a spine x-ray. The population impact and the appropriateness of treatment according to each guideline was evaluated.

Results The population of women over 50 who should be treated according to different guidelines would be $15.5 \%$ (95\% CI 14.0 to 19.0) for CMA, $25.4 \%$ (95\% CI 22.4 to 28.3 ) for SEMERGEN and $36.9 \%$ (95\% CI 33.6 to 40.2 ) for NOF. These figures would be translated into 1.3 to 3.2 million women candidates for treatment in the Spanish NHS. Regarding the appropriateness of anti-osteoporotic treatment, $80 \%, 66 \%$ and $52 \%$ of the women treated $(n=181$; $21.9 \%$ ) did not meet CMA, SEMERGEN and NOF criteria to be treated, respectively. Whereas $16 \%, 23 \%$ and $34 \%$ of untreated women ( $\mathrm{n}=643 ; 78.0 \%$ ) should receive treatment according to CMA, SEMERGEN and NOF guidelines.

Conclusions There are huge differences in the population impact of three commonly used guidelines. Appropriateness of anti-osteoporotic treatment was low due to overuse in women without indication and also because of underuse in women with criteria for treatment.

\section{P1-317 INCIDENCE OF SEVERE WORK-RELATED INJURIES AMONG YOUNG ADULT WORKERS IN BRAZIL- ANALYSIS OF COMPENSATION DATA}

doi:10.1136/jech.2011.142976f.9

\footnotetext{
$1,2 \mathrm{~V}$ Santana, ${ }^{* 2} \mathrm{~A}$ Villaveces, ${ }^{2} \mathrm{~K}$ Bangdwala, ${ }^{2} \mathrm{C}$ Runyan, ${ }^{3} \mathrm{P} \mathrm{R}$ Albuquerque-Oliveira. ${ }^{1}$ Federal University of Bahia, Salvador, Bahia, Brazil; ${ }^{2}$ University of North Carolina, Chapel Hill, North Carolina, USA; ${ }^{3}$ Ministry of Social Security, Brasila, Distrito Federal, Brazil
}

Objectives To obtain national estimates of annual cumulative incidence of severe non-fatal injuries using compensation benefits data from the Brazilian National Social Security Institute (INSS), and to describe their socio-demographic distribution among workers under age 25 .

Methods Data are records of health-related compensation benefits from the Ministry of Social Security's Information System of Compensation Benefits (SUB), of the National Institute of Social Security (INSS), recorded in 2006. The only injuries (International classification of diseases, $10^{\text {th }}$ revision, Chapter XIX) considered were those certified by an INSS occupational physician s workrelated for adolescents and young adults between 16 and 24 years of age.

Results A total of 79899 workers 16-24 years old received a compensation benefit for injuries in the study year, and 19439 (24.33\%) were work-related, 16878 (86.8\%) for males and 2,561 for females (13.2\%). The annual cumulative incidence rate of workrelated injuries (ACSWI) was $3.9 \times 1000$ workers, higher among males $(4.6 \times 1000)$ compared to females $(1.3 \times 1000)$. ACSWI was higher in the younger age group (16-19 years), and there was an income gradient with disproportionately elevated risk in the lowest wage quintiles, especially for females in the younger group. Logging, extraction, food/beverage and construction industries have higher work-related risk for adolescents and young adult workers of both sex groups.

Conclusions These findings suggest that the Brazilian labour laws limiting young adult workers in hazardous settings need to be expanded, adding occupations, extractive industries and certain types of work in the food/beverage manufacturing industries for these workers.

\section{P1-318 LATE PRETERM BIRTH AND RISK OF BEHAVIOURAL PROBLEMS AT 4 YEARS OF AGE}

doi:10.1136/jech.2011.142976f.10

${ }^{1}$ I Santos, ${ }^{*}{ }^{1}$ A Matijasevich, ${ }^{1} \mathrm{~A}$ Barros, ${ }^{2} \mathrm{~L}$ Anselmi. ${ }^{1}$ Federal University of Pelotas, Pelotas, Rio Grande do Sul, Brazil, ${ }^{2}$ Federal University of the State of Rio Grande do Sul, Porto Alegre, Brazil

Introduction Preterm births have been associated with behavioural problems later on. This study aimed to investigate whether late preterm (LPT) children (34-36 weeks gestation) are at increased risk of presenting behavioural problems at the age of 4 years old comparatively to full term children (37-42 weeks).

Methods Children from the 2004 Pelotas Birth Cohort were enrolled just after birth and were followed-up at home in several occasions when information on a series of maternal (socioeconomic, demographic, reproductive, and behavioural characteristics, and maternal depression) and child co-variables (intensive care unit hospitalisation at birth, hospitalisations during the first year, breastfeeding duration and bed-sharing) was collected by trained fieldworkers. Estimated gestational age was based on last menstrual period or, when unknown or inconsistent, through the Dubowitz method. Presence of behavioural problems was assessed through application of the Child Behaviour Checklist (CBCL) to the mothers. Adjusted analyses were run through linear regression.

Results There were 4231 livebirths, $14.5 \%$ were preterm newborns, $77 \%$ of whom were LPT. A total of 3411 children were assessed at the age of 4 years (416 LPT and 2995 full term). Mean CBCL rates were higher for LPT than for full term children (36.6 and 34.2, respectively; $p=0.007$ ). After allowing for confounders (family income, maternal and child characteristics) the association was no longer significant $(\beta=0.4 ; \mathrm{SE}=0.9 ; \mathrm{p}=0.635)$. No interaction was observed between LPT and any of the studied co-variables.

Conclusion LPT children present higher rates in CBCL than term children, but the difference relies mainly on lower socioeconomic conditions. 